\title{
DEL DERECHO A LA ECONOMÍA, Y VICEVERSA. EL REENCUENTRO DESDE EL FACTOR EMPRESARIAL
}

\author{
PAUL LAURENT*
}

Fecha de recepción: 9 de mayo de 2014.

Fecha de aceptación: 17 de octubre de 2014.

Tenía pavor por los seres humanos: le parecían imprevisibles, pero sobre todo perversos y sucios. Las estatuas, en cambio, le proporcionaban una tranquila felicidad, pertenecían a un mundo ordenado, bello y limpio.

ERNESTO SÁbATO

Sobre héroes y tumbas (1961)

\section{INTRODUCCIÓN}

Más allá de los discursos ecuménicos sobre la relación entre el derecho y la economía, todavía las deformaciones constructivistas hacen que cada una de estas ciencias continúen dándose las espaldas. Es decir, estamos ante hermanos siameses que insisten en no verse las caras.

No obstante ello, el peso que la ciencia económica ha venido adquiriendo a lo largo de los últimos años (básicamente desde fines del siglo XX) ha contribuido a una aproximación que nunca tuvo que ser traumática. Pero lo es en la medida en que a lo largo de la última centuria la ciencia jurídica viró por la senda conductista que poco o nada tenía que ver con la esencia liberal del derecho.

* Investigador del Centro de Investigación y Estudios Legales (CITEL). El presente texto tuvo su origen en una ponencia presentada en el I Congreso Internacional de Derecho Empresarial organizado por la Facultad de Derecho y Ciencias Políticas de la Universidad Alas Peruanas, filial Ica (8 de noviembre de 2013). 
En este último punto, la progresiva destrucción de lo que en su día Charles Beudant (en Le droit individuel et l'etat, 1891) denominó la science de la liberté fue diluyendo aquello que desde el siglo XVI la corriente iusnaturalista había pergeñado en su intento de recuperar el derecho romano republicano para engarzarlo con una novedad aún más oscura e incomprendida: el individuo. Ya solo será cuestión de auscultar lo que ese factor ha venido significando, siendo acaso el concepto de empresarialidad el que mejor lo sopese.

Tal es como el derecho y la economía se reencuentran, recuperando un cauce que en su día el constitucionalismo (el del siglo XIX) lo tuvo como propio. Así pues, será la rehabilitación de esta matriz eminentemente empírica de la economía y del derecho lo que trataremos a lo largo de este breve ensayo.

Muy a pesar de los tiempos en los que vivimos, desde hace más de un siglo lo que entendemos por «orden constitucional» se rige por el lamento de Dante frente a las puertas del Infierno (Canto III): ¡Ah, los que entráis aquí, dejad toda esperanza! Así es, el derecho vigente no está para proteger libertades. Desde la irrupción de las corrientes positivistas, conductistas y socializantes de fines del siglo XIX, el vigor libertario que algún día tuvo se ha extraviado.

En esa línea, cuando en 1920 el jurista francés León Duguit volvió a presentar su libro Las transformaciones generales del derecho privado desde el Código de Napoleón (1913), lo hizo para alardear de una «manifiesta evolución» en el campo jurídico. Concebía que el aún imperante "orden metafísico e individualista» estaba siendo sustituido por un sistema jurídico de orden realista y socialista. A su decir, el viraje estaba dado: «la noción de derecho subjetivo se encuentra totalmente arruinada». ${ }^{1}$ Por lo mismo, «el concepto de la propiedad-función (...) poco a poco ha sustituido completamente a la de propiedad-derecho». ${ }^{2}$

\footnotetext{
1 Duguit (1913, p. 29)

2 (Id., p. 9).
} 
Así pues, toda una tradición legal de dos milenios y medio que buscaba conjugar la libertad en el derecho fue dejada de lado. Definitivamente se rompía con la vocación de ponderar la ley como directa consecuencia de la propiedad, base a su vez de la libertad individual (un derecho anterior y superior al estado; ergo, un derecho innato desde la perspectiva del iusnaturalismo clásico).

Tal es como el referido publicista galo celebró el ocaso de un modo de concebir el derecho. Un derecho que brotaba de una civilización forjada desde el rigor de una urbanidad surgida desde el comercio, desde los mercados. No de una urbanidad mustia y autárquica, sino de una urbanidad exuberante y dinámica en relación con análogos emporios mercantiles. Al fin y al cabo, el origen de esa manera de entender el derecho estuvo en una ciudad que se hizo «mundo» liándose con otras ciudades y otros mundos: Roma.

Como se infiere, el festejo de Duguit se montaba sobre el cadáver del directo legado de una urbe que le enseñó a Occidente a colegir que el derecho era sinónimo de libertad, de una libertad que fue abriéndole campo a los hombres hasta el grado de obsequiarles la posibilidad de ya no necesitar de mayor permiso para existir. Les era suficiente darle rienda suelta a su propia volición de sui iuris (de sujetos de derecho). La sociedad de libre empresa que caracterizó al siglo XIX se sustentó en esa forma de calibrar lo jurídico. Pero al concluir la Primera Guerra Mundial (1914-1919) ese mundo había sido liquidado.

$\mathrm{Al}$ amparo de ese conflicto, Duguit juzgará que había lecciones que recoger. Nunca reparó en el detalle de que las guerras invitan a hacer de la excepción la regla. Como muchos de su generación, no asumía que el individuo en sí pudiera aportar socialmente. Lo consideraba una contradicción in adjecto. Sopesará que solo el individuo que se subsuma en el colectivo procede conforme a derecho. Desde ese discurso, la propiedad solo será dable si es que cumple una «función social». En términos de Augusto Comte (citando su Sysèteme de politique positive de 1850), reivindica a un «ciudadano» perfectamente equiparable al funcionario público.

Como parte de ese «novísimo razonar», la supresión del individuo en sí arrastró igualmente la supresión de su «egocéntrica subjetividad». Desde entonces «lo constitucional» tiene mucho que ver con órdenes y mandatos, limitaciones y regulaciones, y 
muy poco con derechos y libertades. Así es como se daba paso a un derecho sin voluntad, a una voluntad sin derecho. En palabras de Marco Aurelio Risolía, «el drama más hondo de la ciencia jurídica.» ${ }^{3}$

Queda claro que antes de la incursión de las ideas socializadoras, la primacía de lo subjetivo (lo práctico) activaba al derecho. No obstante ello, desde sus orígenes la noción de lo constitucional impulsó un afán tuitivo y paternalista por parte de la comunidad hacia cada uno de los miembros de la misma. Mas ello no significó que se confunda tan fácilmente entre lo que son disposiciones ajustadas a derecho frente a lo que son prescripciones puramente políticas.

Durante siglos las fronteras entre ambos soportes estuvieron visiblemente separadas. Pero precisamente a partir del auge del conductismo positivista esos límites se diluyeron. Obviamente esa confusión no fue accidental. Era parte de la ilusión racionalista de asir la realidad y manipularla. En tal medida, se juzgaba a la existencia humana como un hecho dado antes que como un proceso.

Por esa causa, la vida de la gente era susceptible de ser perfeccionada. Innegablemente, el libre albedrío (defendido hasta cierto límite por el iusnaturalismo clásico) acarreaba un mayúsculo inconveniente: le daba al ser humano la posibilidad de disentir de lo oficial, de emprender por su propia cuenta y riesgo y de dar paso a un concierto moldeado desde esa tracción. Mas las corrientes behavioristas repararán que si las cosas se daban libérrimamente, entonces ¿dónde quedaba lo social? En términos iluministas, ¿dónde quedaba lo científico con esa libertad a cuestas? ¿Cómo pensar en un orden predecible si se da cabida a lo puramente particular, a lo disperso? En concreto, ¿cómo sustentar una vida en sociedad desde esa proliferación de individualidades que únicamente miran el mundo desde su propia parcela y carecen de un telos director?

3 Risolia (1958, p. 36). 
La moderna teoría legal no estaba para soportar ese nivel de dispersión y asonancia. De dispersión y de asonancia frente a lo estatal, se entiende. Hoy por hoy, lo estatal casi es símil de lo constitucional. No en vano Félix Somló (rememorado por García Maynez) juzgaba a la teoría general del derecho (Allgemeine Rechtslehre) como una disciplina nomográfica, limitada «a exponer y sistematizar el contenido de prescripciones ya formuladas. ${ }^{4}$

El tenor positivista no puede ser más evidente. $Y$ desde ello la moral providencialista tampoco (la esclavitud del porvenir, espetará Spencer). Un abanico de excesos imposibles de evitar. Si el citado García Maynez se esfuerza por remarcar que el derecho no tiene como fin hacer mejores a los hombres, no puede eludir manifestar que ese impedimento «puede y debe asegurar las condiciones que les permiten cumplir su destino ético y desenvolver su personalidad moral.» ${ }^{5}$ Sin duda, he ahí el mínimo de seguridad, justicia y solidaridad que Fernández Sessarego exige como los supremos valores de la Caridad y el Amor del aparato lógico-normativo. ${ }^{6}$ En palabras de Hayek (totalmente crítico a los postulados de los autores antes citados), la búsqueda de fines tangibles es característica de sociedades tribales (de hombres dirigidos) antes que de sociedades abiertas (de hombres libres). Siendo que solo en las primeras se tiene presente «la voluntad de alguien que puede decir en todo momento cuáles son esos fines y cuál es la oportuna manera de alcanzarlos». ${ }^{7}$

Bajo la visión behaviorista no es dable inferir un orden social al margen de un ente ordenador. Y con un fin incluido. De plano, se descarta lo impredecible. Se rechaza lo empírico, el saber esencialmente tácito, no articulable, no consciente. Los elementos a ser ordenados tendrán que estar a entera disposición de los requerimientos del ordenador. De otro modo la tarea de este último carecerá de sentido. Una pretensión que el constitucionalismo ha sobrevalorado en los últimos cien años al extremo de desbordar sus propios diques de contención para proceder a negar el concierto

\footnotetext{
${ }^{4}$ García Maynez (1974, p. 12).

5 (Id., p. 105).

${ }^{6}$ Cfr. Fernández Sessarego (1987, pp. 131-132).

7 Hayek (1976, p. 237).
} 
que a su vez estaba inicialmente llamado a defender: el de los derechos tenidos como libertades.

III

No hay duda de que el problema de origen del constitucionalismo (su congénita vocación celadora) adquirió un volumen de magna desmesura al ser capturado por discursos redistributivos que le daban más relevancia a liberar al poder político que a controlarlo. Así, la vieja misión del constitucionalismo se apagó. Ahora su nueva misión pasaba por abrir las compuertas a las otrora "pequeñas» injerencias gubernamentales, desatando las amarras que le impedían tomar para sí las riendas de lo social. Desde ese instante, será el estado el encargado de hacerse cargo (directa e indirectamente) de ese cometido.

El orden de mercado que en su momento fue apuntalado por el constitucionalismo decimonónico (el «constitucionalismo clásico») pasó de la aclamación al repudio. La acusación principal contra el esquema que se reemplazaba estaba en su falta de finalidad, de ser impredecible e irracional.

Cuando a fines del siglo XX (exactamente en 1985) los economistas James Buchanan y Geoffrey Brennan indiquen que la ciencia económica es (o debería de ser) reflexión sobre el comportamiento individual en sociedad, ${ }^{8}$ expresarán una verdad que antaño estaba inserta en el campo de la ciencia jurídica. Será parte del rescate de un aserto que va de la mano de la lamentable verdad que dice que la idea de que las constituciones definen los limites de la autoridad política es una abstracción que a muchos les cuesta comprender. ${ }^{9}$

Si la ciencia jurídica se había negado a ver las cosas en su propia dinámica y discurrir, lo había hecho afiliándose a la moda antiliberal que apostaba por la planificación centralizada de los comportamientos humanos antes que el dejar hacer y el dejar pasar de los mismos. Esta apuesta por asumir a la sociedad desde la óptica del ingeniero social (el mundo de las formas y de las ideas)

\footnotetext{
${ }^{8}$ Brennan y Buchanan (1985, p. 39).

9 (Id., p. 65).
} 
apuntalará una visión de lo político que en su día hombres como Tocqueville entendieron como próximas a ser superadas. Empero la fascinación por la razón que la ilustración alentó aún tendrá mucho que decir, aconteciendo que su principal invocación sobrevivirá a su estrepitoso fracaso: pautar racionalmente los actos humanos.

Qué extraño sonaba ahora que un gobernante como Cromwell (dictador, para más señas) concibiera que nunca el hombre llega más alto como cuando no sabe ni por asomo a dónde va. Si partimos del nostálgico recuerdo de pensadores como Popper evocando a Hipodamo de Mileto (diseñador de ciudades) como el primer ingeniero social de la historia, es más que palmaria la convicción de que las sociedades no pueden funcionar «racionalmente» por sí mismas. ${ }^{10}$ Por ende, cualquier propuesta distinta a esa convicción habrá de ser tenida como irracional. ¿A quién se la ha ocurrido creer que las sociedades pueden evolucionar sin un director a cuestas?

Ya hemos visto que juristas como Duguit alegaban que la edad del «orden metafísico e individualista» había quedado atrás. Ese parecer se replicará en diferentes campos del saber, reforzando el criterio de la imperiosa necesidad de un ente capaz de dar normas y directivas a una ciudadanía por naturaleza anárquica. No bastará que autores como Raymond Ruyer (L'Utopie et les utopies, 1950) contraargumenten diciendo que: «Mientras que los imperios y constituciones más duraderos han sido edificados sin ideas preconcebidas y sin planes generales, las estructuras proyectadas con demasiada minuciosidad solo han durado lo bastante para caer pesadamente lo mismo sobre los constructores que sobre los espectadores.»11

Cuando Hayek expresaba (evocando al escocés Adam Ferguson) que las sociedades son resultado de la acción humana, pero no del designio humano, estaba sacando a la luz una manera de

\footnotetext{
10 Popper (1945, p. 453).

11 Cit. por Sartori (1965, p. 237).
} 
auscultar lo social le ofrece a lo legal un reencuentro con un orden al que en su momento se decidió no ver más por exceso de razón. Tal es como nos brindará una aproximación a un cosmos generado sin intención, que es directa consecuencia del proceder de individuos que no tienen más miras que la de satisfacer sus singulares objetivos.

A pesar de esas personales apetencias tenidas en principio como asociales, aquellos «egos» activarán (sin proponérselo) una institucionalidad tan predecible como social. Sin embargo, la moderna legalidad la sopesará desde la sospecha por pura incomprensión. Tempranamente la ciencia económica había advertido esa situación, comenzando por la incomprendida mano invisible de Adam Smith. Un hecho solo dable a partir de la existencia de derechos. Sin duda, en Smith esa advertencia confirmaba la premisa básica de un iusnaturalismo aún hegemónico. Ello tanto en el ámbito del derecho europeo-continental como en el del derecho anglosajón, sin descontar las singularidades de cada una de esas legalidades. El derecho mercantil y el common law se movieron sobre ese cauce; en el caso del derecho inglés, muy a pesar de las injerencias de los tribunales reales (injerencias siempre extraordinarias).

No obstante que en el derecho europeo-continental el factor político tenía una sobredimensionada preeminencia, la convicción en favor de un orden legal superior y anterior al oficio del legislador dominaba. Indiscutiblemente, en el esquema anglosajón esa convicción era mayor, pues comparado con el sistema legal europeo-continental la insularidad inglesa siempre se caracterizó por ser menos dependiente de lo político. Claro, todo ello hasta el quiebre epistemológico que significó la instauración del positivismo a fines del siglo XIX (iniciada desde el «derecho divino de los Parlamentos», según Spencer). Ese mismo siglo donde los usos y costumbres de los comerciantes entraron a formar parte del ordenamiento jurídico. ${ }^{12}$ Un evidente retorno a lo elemental. No en vano un erudito apuntaba que la decadencia romana tenía mucho que ver con la sustitución de la legalidad de los marineros por la legalidad de los emperadores. ${ }^{13}$

\footnotetext{
12 Benson (1990, p. 261).

13 Cfr. Baynes (1925, p. 180).
} 
Si hasta ese momento la ciencia jurídica compartía con la ciencia económica el interés por vislumbrar las consecuencias no intencionadas de la acción humana (sea a través de leyes económicas como de pautas jurídicas nacidas en ese mismo espacio privado), rápidamente se dará un repliegue por parte del derecho. Y esa ruptura acontecerá hasta el grado de borrar de la memoria el recuerdo de que un profesor de jurisprudencia fue el primero en tratar sistemáticamente de temas comerciales: el ya citado Adam Smith.

A poco más de un siglo, ese interés por las consecuencias no intencionadas de la acción humana se concentrará exclusivamente en la economía. La «revolución subjetiva» o «marginalista» de la década de 1870 promovida primordialmente por economistas austriacos confirmará ello. Como ejemplo, para el economista Carl Menger (como para el filósofo evolucionista Herbert Spencer) las instituciones serán producto de la interacción de muchos hombres, pero sin que ninguno de estos en particular se erija en exclusivo constructor de dichas instituciones. Exactamente lo que el jurista alemán Jhering desmenuzaba a partir de su ciencia en esos años, hablando de que son dos los momentos integrantes del concepto del derecho: uno sustancial, en que reside el fin práctico de éste, a saber, la utilidad, provecho o ganancia que debe garantizar; y otro formal, que en relación con el fin aparece simplemente como medio, a saber, la protección jurídica, la acción en justicia. ${ }^{14}$

Curiosamente los dos momentos integrantes del concepto del derecho del jurista Jhering el economista Menger los desarrollará para el campo económico en el libro inaugural de la «escuela austriaca», Principios de economía política (1871). Como resaltaba Lachmann (salvando las diferencias entre lo histórico y lo teórico), en esa obra Menger hablaba del método de comprensión (Verstehen) como el método característico de las ciencias sociales. La teología, la jurisprudencia, la filología y la historia lo tuvieron como suyo desde antiguo. ${ }^{15}$

Puntualmente en Problems in Economics and Sociology (1883) Menger dirá que la economía no será ajena a ese instrumento, aunque

14 Cfr. Jhering (1852-1865, p. 365).

15 Lachmann (1966). 
partiendo desde su propio logos. ¿Una salida análoga a la que los empíricos romanos dieron a su legalidad (la ciceroniana leges legum que constreñía a los magistrados, frenando su arbitrariedad)? ¿No son esos logos los que andan buscando sus respectivas leyes? ¿Como en el derecho anglosajón, donde se tiene por "constitución» antes que un texto escrito filosóficamente elevado (preconcebido) un elemental y práctico conjunto de "principios básicos»?

Tocante a esos tópicos, un revolucionario como Pašukanis subrayará que «(...) una construcción jurídica, aun cuando pueda parecer artificiosa e irreal, mientras permanece en el ámbito del derecho privado y en especial bajo el perfil del derecho patrimonial, se apoya en terreno sólido.» ${ }^{16}$ Agregando que si las líneas fundamentales del pensamiento jurídico romano aún sobreviven es porque siguen siendo la ratio scripta de cualquier tipo de sociedad productora de mercancías.

Si empalmamos este discurrir con el aforismo latino ubi societas ubi ius (donde hay sociedad hay derecho) no será nada complicado confirmar que la relación entre individuo y sociedad es indesligable, desmintiendo de partida la afirmación de que el individuo en sí es un elemento disociador y contrario a los intereses de sus semejantes. Y en ese desmentir la subjetividad elevada al rango de ius (de derecho) invita a pensar en una voluntad capaz de justificar legalmente a quien únicamente necesita valerse por propia cuenta tanto para su propio beneficio como para el de su comunidad.

En sus Ensayos el pensador renacentista Michel de Montaigne escribía que en la voluntad se fundan y se establecen todas las reglas del deber del hombre (L. I, Cap. VII). No por accidente los romanos habían establecido que el solo consenso obliga (solus consensus obligat). Un consenso que con el paso del tiempo y de la buena reputación se hace ley por mero uso. Unas normas surgidas de los

16 Pašukanis (1924, p. 68). 
acuerdos recíprocos de una multitud de particulares que inicialmente se acogieron a meras prácticas y costumbres, opiniones y valores comunes.

Todo ello en un plano primario. En un plano más avanzado ese nivel de convivencia y cooperación requerirá de ese mismo soporte, pero lo suficientemente evolucionado como para ser debidamente aprovechado por una comunidad ahora mayormente conformada por participantes no precisamente conocidos. Indudablemente, nuevas demandas estimulan nuevos esfuerzos; y cada esfuerzo será recompensado con una base de subsistencia más amplia y segura. Por ende, con nuevas empresas.

Dependiendo del nivel de asimilación de personas desconocidas entre sí, sabremos de una institucionalidad realmente idónea para esos particulares que únicamente buscarán el mejor ambiente para explayar sus proyectos individuales. En solitario y sin las instituciones pertinentes para concurrir con seguridad, esos «endemoniados egos» no estarán en condiciones de generar beneficios sociales de ningún tipo, salvo el derrotero hacia donde poder huir.

Sin cinismo de por medio, hallar la mejor ruta de escape también es un don de pocos. Un don que nutrirá al lugar que los acoja. Por lo mismo, no será complicado interpretar que el suelo del que se huyó sufrirá una merma. Se descapitalizará, viendo cómo se marchan hacia otras tierras personas que solo pedían el mínimo de ética necesaria (expresión de Jellinek para concebir al derecho) para poder dar rienda suelta a lo hoy denominamos empresarialidad.

¿No era eso lo que Jhering tenía como la propia definición del derecho: un interés individual jurídicamente protegido? Este jurista (y su generación) tenían en claro que nadie existe solo para sí ni por sí solo, sino que se existe por y para los otros, sea intencionadamente o no. Así, si el egoísmo lo quiere todo para sí, el mundo lo toma a su servicio y le paga el salario que reclama. Lo interesa en sus fines $y$ desde luego está seguro de su concurso. ${ }^{17}$ En conclusión: «El derecho autoriza el libre funcionamiento del egoísmo, siempre que

17 Jhering (1877-1883, p. 22). 
en la persecución de su fin se abstenga de recurrir a medios prohibidos.»18

Bajo esa hoy olvidada premisa tendrá que ser un economista (Jesús Huerta de Soto) el que abogue que: «Todos los hombres, al actuar, en mayor o menor medida, con más o menos éxito, ejercen la función empresarial». ${ }^{19}$ Ciertamente lo entiende como el pleno ejercicio de un derecho. De un derecho natural, dirían los antiguos juristas. Tal es el punto de partida de quienes se juzgan capaces dar rienda suelta a su empeño por descubrir nuevos horizontes de socialización, que así es como debe de verse el universo de la empresarialidad y el comercio. Esos nuevos horizontes que solo podrán florecer si es que las vallas legales e institucionales alientan un amplio margen de movilidad, garantizando una concurrencia capaz de regular por sí misma a los avasallantes egoísmos. Según Jhering, he ahí a un regulador espontáneo. ${ }^{20}$

Como vemos, la competencia era tenida como un eficiente equilibrador de intereses contrapuestos. La mejor manera que tienen los miembros de la sociedad para beneficiarse del esfuerzo de sus semejantes. Obviamente, sin intercambio la sociedad no existe. Su fuerza y sanidad estará en la profusión de estos, haciendo más fácil y llevadera la vida de las personas a partir de esa atomizada comunicación de bienes y servicios que no es más que parte de un ininterrumpido proceso de descubrimiento que nos lleva a responder inconscientemente a nuevas situaciones. En ese sentido, a mayor nivel de población (pues habrá más potenciales empresarios) mayores posibilidades de soluciones sociales con su correspondiente afinación jurídica.

Sin duda, el solo hecho de hacer referencia a un ininterrumpido proceso de descubrimiento anula la premisa de teorías que parten del supuesto de un orden ya dado, donde (por estar todo ya dado) no habrá nada que descubrir. Y si ya no hay nada que descubrir tanto economías como derechos serán «resueltos» desde ámbitos técnico-gubernamentales antes que desde la mera competencia que se funda en los contratos (en los usos y costumbres de

\footnotetext{
18 (Id., pp. 64-65).

19 Huerta de Soto (1992, p. 73).

20 Cfr. Jhering (1877-1883, p. 71).
} 
los comerciantes). Es el reemplazo de las capacidades y conocimientos de los privados por parte de una lejana burocracia estatal. Los primeros (los privados) conocerán de hechos, y de leyes adscritas a esos hechos; los segundos (la lejana burocracia estatal) de teorías, sobre las que se redactará una frondosa y enrevesada legislación a la que poco o nada le importará los hechos, ni muchos menos las leyes que nacen por exigencia de esos hechos. ¿Acaso no es la llamada «economía informal» un campo de derechos negados? Palmariamente, esa negación proviene de un ente ajeno que se impone compulsivamente (manu militari) y obliga a esas economías (y a esos derechos) a moverse en las sombras.

Esta desconexión de lo estatal frente a lo empírico arrastra la negación de la acción humana, punto de origen de un universo de interrelaciones que a su vez parte de un reconocimiento (más tácito que explícito) a una legalidad previa, de derechos innatos. Una inmaterial herramienta surgida de la eterna brega del ser humano por agenciarse los mecanismos más idóneos de socialización, pero siempre reivindicando su particularidad. Comprensiblemente, sin dicha función empresarial ninguna sociedad es concebible. Y no lo será porque negarla será negar el libre ejercicio de derechos, los que no son más que directas consecuencias de una individualidad reconocida como una esfera de propiedad única y exclusiva, capaz de ser reivindicada contra todos (erga ommes). Por lo tanto, capaz de ser libremente transferida. Una libertad no inocente, sino intencionada. Pero no por ello predecible.

Aquí lo único seguro es que el derecho le da al hombre la posibilidad de actuar. Por ende, toda acción humana (toda especulación) será racional en tanto que vaya acorde al derecho que sustenta esa potencial capacidad de emprender, de descubrir. Tal es como Richard Cantillon (en su Essai sur la nature du commerce en general de 1755) introdujo el galicismo entrepreneur, refiriéndose al «especialista» que afronta riesgos y que se mueve en la incertidumbre. Un proceder (un derecho) que a decir de Israel Kirzner se sustenta más en la perspicacia de quien sabe por intuición donde toparse con «las oportunidades que ya existen y que están esperando que alguien las descubra.» 21

${ }^{21}$ Kirzner (1973, p. 99). 


\section{VI}

El economista austriaco Ludwig von Mises entendía que en toda economía real y viva todo actor es siempre un empresario. ${ }^{22}$ Innegablemente la calidad de la acción de ese empresario (un término aplicable a toda persona, a todo «sujeto de derecho») irá acorde con su esfera de libertad reconocida. Ahora, si un sui iuris (el empresario) actúa, ¿será pertinente concebir un orden preexistente a su acción? Es decir, ¿se puede hablar de empresarialidad y de derechos si es que a esa empresarialidad y a esos derechos se les anula la incertidumbre para obsequiarles la más completa de las certezas? Puntualmente, ¿es dable alegar que es posible proceder de acuerdo a derecho solo en la medida que calibramos un concierto de opciones legales limitadas a priori?

De ser ello así sería totalmente irrelevante y hasta perjudicial el factor «ignorancia» (el no saber), el mismo que ha ido radicalizándose ni bien las sociedades han ampliado su población y se han liado con otras sociedades más densas en capacidades individuales. Verdad, es precisamente esa abundancia de opciones lo que afianza la imposibilidad de poder preverlo todo, ni siquiera una parte importante.

Ello en sí rebaja grandemente (o debería) la pretensión holística del potencial constituyente o legislador, de un ordenador de naciones. La única manera que se justifica la existencia de estos portentos es que los mismos rebajen sus pretensiones, pasando a convertirse en árbitros de los cotidianos conflictos entre los privados (a la usanza del antiguo pretor romano). ¿Es esa la labor del ordenador de lo común (sea constituyente o legislador)? Lamentablemente, todo indica que no.

A pesar del riesgo de ser desbordados, la vocación holística y planificadora de lo político-estatal sigue en pie. El grueso de las escuelas económicas y jurídicas responden a ese pensamiento, prefigurando un mercado y una legalidad donde las personas solo pueden «descubrir» («innovar») a partir de lo teóricamente pautado. Que se imponga la forma (el ideal) a lo empírico por

22 Mises (1949, p. 307). 
imposibilidad de aprehender la realidad no es igual a que ella se imponga no obstante lo formal. Si se renuncia a la comprensión de lo que acontece en los hechos por predilección a una teoría, poco es lo que esa teoría podrá ofrecerle a los hechos.

Como la teoría económica, el derecho mira las cosas acaecidas con mucha posterioridad. Por algo es también teoría. Una teoría que mira y ausculta a los portadores de derechos que generan un orden (una regularidad de comportamientos) la más de las veces marginal a lo oficialmente prescrito (mayormente inspirado en alguna teoría divorciada de lo empírico). En esa línea, la diferencia entre economía y derecho (como teorías) es que la primera observa sin valorar mientras y el segundo lo valora todo (sea el proceder individual como el del conjunto). Y si medimos le legalidad y la economía como meros problemas técnicos (de asignación, maximización u optimización de información), desembocaremos en la premisa de que los que ejercen derechos y emprenden responden a lineamientos burocráticos antes que a lineamientos jurídicos y económicos adscritos al discurrir del ininterrumpido proceso de descubrimiento donde la incertidumbre marca la pauta.

Como se decanta, si asumimos la empresarialidad y la gama de derechos que la hacen posible (como los de propiedad y de libertad contractual), no tendrá sentido invocar la existencia de un «conocimiento perfecto» (cargado de información justa y precisa). En términos de Kirzner, ese tipo de conocimiento excluye por definición oportunidades de ganancias no explotadas. Y las excluye porque bajo ese esquema un formalmente catalogado como «sujeto de derecho» no tiene nada que hacer, no tiene campo para ejercitar una toma de decisiones.

Para descubrir esas oportunidades no explotadas solo será necesario ejercer derechos fuera de los modelos apriorísticamente establecidos. Fuera de esa institucionalidad altamente limitante, las expectativas para descubrir oportunidades invitarán a que se exijan derechos para salvaguardar los logros (las ganancias) de ese emprendimiento. Tal es lo que los teóricos no empíricos suelen despreciar, esa inmensa cantidad de cazadores de fortuna que no tienen más conocimiento que su intuición. Un saber no transmisible, sino puramente personal. En palabras de Kirzner: «El cálculo no ayuda a nada, ni la economicidad ni la optimización, 
por sí mismas, proporcionan este conocimiento. Así, la decisión de nuestro nuevo autor de decisiones no se puede, en absoluto, "leer" a partir de los datos; no está implícita en las circunstancias en que se encuentra colocado.» ${ }^{23}$

\section{VII}

La convicción de Kirzner de que la sociedad (el mercado) no es una concepción ya dada (de equilibrio puro y permanente), es categórica en la medida que colige que la interrelación humana es un proceso de constante descubrimiento (puntualmente dirá que se halla en un constante estado de flujo, nunca está en equilibrio ni se acerca a él). Siendo que esa es su característica primordial, será sencillo advertir que se está ante frecuentes reacomodos y revisiones de quienes ejerciendo sus derechos innatos (a través de una cadena ininterrumpida de relaciones jurídicas, diría Pašukanis) van calibrando los mismos en aras de alcanzar sus personales objetivos. Un transitar que a la vez indica la relevancia de esa institucionalidad (y de la atmósfera moral que la sustenta) en la viabilidad de esa sociedad o mercado.

Ante lo expuesto, la perenne innovación surge por la «imperfección» concomitante a ese concierto de egos pugnando por estirar lo más posible sus pretensiones. Unos «derechos» que son siempre una posibilidad para actuar, pero no por ello son de por sí una garantía de éxito. Siendo que si la perfección dominara el escenario, la motivación para emprender perdería fuerza. Ya únicamente se tendría que recurrir a una oficina gubernamental antes que al mercado, pues si lo perfecto manda la política estatal (la que juzga que todo lo sabe) se montará sobre los derechos.

De regir un orden económico-legal en el que no debería de haber «errores» (por lo que de plano se les tiene como fallas a ser saneadas legislativamente), se estropearían los incentivos por los cuales los emprendedores encuentran su motivación para actuar, para ejercer derechos, para detectar novedades y desde ellas

${ }^{23}$ Cit. por Huerta de Soto (1987, pp. 57-98). 
corregir los aparentes desequilibrios de dicho orden. Como dice Kirzner: Una visión del mundo siempre en equilibrio deja de lado demasiados rasgos de la realidad como para ser útil en el pensar económico. ${ }^{24}$

En plena efervescencia revolucionaria soviética, el jurista bolchevique Evgeni Pašukanis concluyó que si se desconoce lo privado (justificado desde los derechos innatos) hablar de derechos carecería de sentido. Ya solo se podrá hablar de órdenes y de mandatos desde el poder. Si los derechos solo tienen razón de ser en medio de la incertidumbre, en una sociedad dirigida por un ente organizador esos derechos se vuelven irrelevantes. No por nada Pašukanis sentenció en jerga marxista-leninista que: «La sociedad burguesa capitalista, únicamente, es la que crea todas las condiciones necesarias para que el momento jurídico asuma en las relaciones sociales su plena determinación.» ${ }^{25}$ Vislumbraba que la caída del derecho burgués no significaba el advenimiento de ningún derecho proletario, pues simplemente en este estadio no habría derecho alguno.

Como la economía práctica, el derecho práctico «no es más que la circulación de mercancías». A decir de Marx, la célula básica del capitalismo. Aquello que en Historia y conciencia de clase (1923) Györy Lukács convertirá en una teoría del fetichismo que determinará a todo el orden social. Y todo porque es circulación, todo un proceso no deliberado ni preestablecido. Detalle que ni Marx ni Lukács querían entender. Así, tal es como ese primario proceder activa instituciones no solo jurídico-económicas, sino también morales.

Al respecto, es sintomático que haya sido Adam Smith el que refiera (desde sus clases de jurisprudencia) que la probidad y la puntualidad siempre acompañan al comercio: De todas las naciones de Europa, los holandeses, los más comerciantes, son los que más cumplen con su palabra. (...) Esto no ha de ser imputado en absoluto al carácter nacional como algunos pretenden. No existe ninguna razón natural por la cual un inglés o un escocés no pudieran ser tan puntuales en cumplir sus compromisos como un holandés. Está mucho más relacionado con el propio interés, ese principio general que regula las acciones de todos los hombres, y que lleva a los hombres a actuar de cierta

\footnotetext{
24 Kirzner (1992, p. 42).

25 Pašukanis (1924, p. 44).
} 
forma considerando la ventaja (...) Donde la gente pocas veces negocia una con otra, vemos que están un poco dispuestas a engañar, porque pueden ganar más de una treta ingeniosa que lo que pueden perder por el daño que esto inflige en su carácter. ${ }^{26}$

Indudablemente, los alcances de la socialización llegan a su más elevada expresión cuando más amplias son las posibilidades de los actores que se involucran en ella. Para que ello sea dable solo será necesario tener el acceso lo más limpio de obstáculos para participar en dicha interrelación y encontrarle el mayor de los provechos. Ello en términos tanto económicos como jurídicos no tiene otra denominación más que el de libertad, la libertad del agente económico y jurídico de emprender y poder disfrutar los logros de esa libertad ejercida. En alocución de Kirzner, la circunstancia crucial que les permite a los mercados funcionar.

\section{VIII}

Como la economía, el derecho también surge de una escasez que invita a la comunicación. Por lógica, si todo abundara y las necesidades no existieran, ¿para qué socializar intercambiando derechos (bienes, mercancías)? Por ende, se está ante una comunicación que atemperará los imponderables de la incertidumbre del no tener. Se redimensiona la relevancia de un derecho capaz de hacerse fuerte desde el no saber lo que vendrá, que invita a una libertad cargada de posibilidades infinitas (imposibles de ser vistas de antemano).

Sin la incertidumbre y sin la escasez ni la economía ni el derecho existirían. Por lo mismo, si todo abundara y fuera sabido por adelantado no tendría ninguna importancia especular ni el distinguir entre lo mío y lo tuyo. En un plano superlativo, gracias a ese discurrir se puede hablar de un proceso constitucionalizador antes que de una constitución en sí. ¿No es ello lo que nos legó Tito Livio al narrar la historia de Roma? Estrictamente, una constitucionalidad activada desde los propios derechos, y no a pesar de ellos.

26 Smith (1978, p. 538). 
Tal era lo que Hayek tenía en mente cuando decía que «el derecho civil debiera en igual medida limitar el comportamiento de los agentes del gobierno que el del simple ciudadano.» ${ }^{27} \mathrm{Y}$ es de sospechar lo mismo respecto a Pašukanis, quien señalaba que: «Es precisamente en el derecho privado donde las premisas a priori del pensamiento jurídico se revisten de la carne y de la sangre, de las dos partes contendientes que defienden con la vindicta en la mano el "derecho propio"..»28

Por lo apuntado, el derecho (la noción de pertenencia de una mercancía a título individualmente exclusivo) existió desde tiempos remotos. Lo que no se sabe si existió con tanta anterioridad es el nivel de esfera de acción de esa exclusividad individual. La historia solo registra que la individualidad tal como la conocemos (sujeta a una única persona y sin posibilidad de reclamar propiedad sobre la humanidad de nuestros semejantes) data del siglo XVI, justamente el momento en el que derecho natural clásico descollaba. Fuera de ese tempo no sabemos a ciencia cierta desde cuándo exactamente el hombre opuso su posesión de hecho (acaso la posesión de su propio cuerpo o de la cueva donde habitaba) a los intereses de terceros. Así es, no es Roma la que inventa la propiedad ni el derecho adscrito a ella. Innegablemente la pone en valor y la refuerza grandemente, imponiéndole su sello. Ya otras sociedades habían hecho esa tarea. Empero, será Roma la que erija una civilización a su amparo. He ahí la diferencia de su legado.

Desde la prehistoria la gente compra y vende, cede posesiones y contrata, ¿pero realmente desde esa edad se realizan esas transacciones de acuerdo a derecho? Obviamente si se ha llegado a ese nivel de mutuas contraprestaciones es porque existe un piso institucional que las soporta y les permite fructificar. La ausencia de violencia así lo indica. Y ello quizás en virtud a relaciones previas, de antemano arraigadas, las que han permitido a los primitivos contratantes aprovecharlas para aminorar los concomitantes riesgos del incumplimiento.

Ahora, el éxito de este tipo de acuerdos se verifica en la medida de que aún existen. Y que existen en cantidad y son de uso

27 Hayek (1979, p. 65).

28 Pašukanis (1924, p. 66). 
constante desde tiempos inmemoriales. Una apuesta que se ha ido ajustando en sus distintas instancias, no por un proceso lineal de perfección, sino por un proceso meramente instrumental. De su uso en un pequeño espacio de conocidos, igualmente la memoria histórica no alcanza a conocer el momento en el cual los hombres decidieron ampliar sus horizontes y contratar con desconocidos, llegando a despersonalizar las transacciones. Despersonalización que hará del derecho una institución de magno alcance, lo que lo tornará más fino y complejo.

Toda sociedad grande sabe de ese nivel de interrelación. Y lo sabe porque solo así podrá aprovechar al máximo su densidad demográfica, de lo contrario solo será una mera juntura de gente desperdiciando su existencia por no haber descubierto ni mucho menos afinado sus tratos y costumbres, elevándolos al nivel de contratos y normas.

Si la sola aglomeración humana es en sí una promesa de solución a los problemas de la propia aglomeración, esa promesa puede devenir en trunca si es que se carecen de las instancias idóneas para que esa enorme junta de gente sea de provecho. Que una sociedad moderna se rija por medio de los parámetros gregarios y tribales (con jefes que presumen conocer cada una de las necesidades de sus «aldeanos») muy bien puede ocasionar perjuicios antes que soluciones (las hambrunas en Rusia, China e India en el siglo XX se dieron por ese hecho).

\section{IX}

Si al inicio de este ensayo evocamos a Dante no fue sin intención. Él en su libro De la monarquía (1310) brindará acaso la más hermosa concepción del derecho entendido como un proceso social: «El derecho es una proporción real y personal de hombre a hombre, que cuando es mantenida por estos, mantiene a la sociedad, y cuando se corrompe, la corrompe». ${ }^{29}$

Por donde se mire, Dante no antepone el «bien común» (el factor socializador) al derecho personal (derecho individual e innato).

29 Alighieri (1310, p. 68). 
Tampoco lo toma a la inversa, simplemente los tiene como indesligables. Y ello no tiene por qué extrañar, pues estamos ante el parecer de alguien que simplemente emplea su destreza retórica para describir un aserto sobradamente conocido por el que más dentro de un orden que desconoce desmesurados portentos como los del constituyente y el legislador estatal. Sobre éste último personaje, decía Spencer: «no conoce a la milésima parte de los ciudadanos; no ha visto la centésima parte de ellos, únicamente tiene escasas noticias de los hábitos, costumbres y modo de pensar de los mismos; $y$, no obstante, cree firmemente que todos obrarán como él prevé y tenderán al fin que desea ver cumplido.» ${ }^{30}$ La ingenuidad va de la mano del despotismo.

El mundo de Dante Alighieri era el de la ciudad-república, no el del estado-nación. Por ende, el sustrato de la legalidad que conocía era eminentemente práctico, carente de mayores elucubraciones. Clara muestra de que así como los mercados no son compartimentos estancos, la legalidad lo es menos. Ambos son espacios interpretativos (retóricos) de un mismo cuerpo (la sociedad), que solo pueden ser entendidos como procesos sin fin.

Innegablemente el espíritu del comercio tiene mucho que ver en esa practicidad legal. Ayer como hoy, los usos y costumbres de los mercaderes imponen su ritmo, acogiéndose a una institucionalidad aprovechable a sus intereses. Es decir, se mueven en un esquema de normas moldeables desde su actividad. Unas normas no fabricadas por legislador alguno. Mucho menos diseñadas con pretensiones holísticas, demandantes de una legalidad más interesada en responder a la coherencia de los teóricos que a las exigencias prácticas de los ciudadanos con derechos. Soberbia diferencia, la que hace precisar al citado Dante que el Digesto no está para definir lo que es un derecho (en él Julius Paulus prescribía que lo justo no se deriva de la norma, sino que la norma nace de lo que tenemos por justo [non ex regula ius sumatur, sed ex iure quod est regula fiat]). A lo mucho solo podrá describir cómo es que se le utiliza.

El talante de una juridicidad abierta y competitiva (francamente evolutiva), carente de legislador y de constituyente, se expone

30 Spencer (1884, p. 109). 
aquí en todo su esplendor, donde la fascinación por el estadolegislador no entra a tallar. La acción humana se impone y legisla. Aquí lo racional de dicha institucionalidad estará en que surge de la concurrencia de los meros interesados.

Si alguien presume que un orden de esa naturaleza es incapaz de trascender porque carece de fines y objetivos precisos (propios de un estado-nación, dicen el grueso de los publicistas), advierte un defecto ahí donde hay una virtud. Cierto, es justamente esa ausencia de fines y objetivos precisos lo que da cabida a que sean los derechos tenidos como innatos a todo ciudadano los que den vida a una constitucionalidad ad hoc, surgida de unas libertades que se ejercen y evolucionan constantemente antes que ellas surjan desde una constitucionalidad extraña a esas libertades.

Pensar que la constitucionalidad que se produce desde la interacción de millones de seres humanos es sinónimo de caos y de anarquía es negar la esencia del proceso social que hasta ahora ha sido comprendido por una parte de la ciencia económica a la vez que totalmente negado por el derecho moderno. Y si la diferencia entre una ciencia y la otra está en que la primera no legisla y la segunda sí, fácilmente se entenderá la desconexión del derecho positivo ya no solo con las reglas de la economía, sino con los mercados: En el volumen tercero de Derecho, legislación y libertad (1979) Hayek señaló que en ningún momento ha diseñado el hombre el sistema económico en el que desarrolla su actividad, porque no somos lo suficientemente inteligentes para hacerlo. Empero, al parecer sí nos presumimos lo suficientemente «inteligentes» para diseñar sistemas legales que condicionan a ese sistema económico que no se puede diseñar.

\section{REFERENCIAS BIBLIOGRÁFICAS}

Alighieri, D. (1310): De la monarquía, Losada, Buenos Aires, 1966. - (1304-1321): La divina comedia, Edaf, Madrid, 1989.

BAYNES, N.H. (1925): El imperio bizantino, Fondo de Cultura Económica, México D.F., 2. ㄹ ed., 1951.

BENSON, B.L. (1990): Justicia sin Estado, Unión Editorial, Madrid, 2000. 
BRENNAN, G. y BUCHANAN, J. (1985): La razón de las normas. Economía política constitucional, Unión Editorial, Madrid, 1987.

CANTILlon, R. (1755): Essai sur la nature du commerce en general, Reissued for The Royal Economic Society by Frank Cass and Co., Ltd., London, 1959.

Duguit, L. (1913): Las transformaciones generales del Derecho privado desde el Código de Napoleón, Librería de Francisco Beltrán, Madrid, s/f.

Fernández Sessarego, C. (1987): El derecho como libertad. Preliminares para una Filosofía del Derecho, Universidad de Lima, Lima, 1994.

García Maynez, E. (1974): Filosofía del Derecho, Porrúa, México, D.F.

HAYEK, F. (1952): The counter-revolution of sciencie: Studies on the abuse of reason, The Free Press, 3. ㄹ. ed., New York, 1964.

- (1960). Los fundamentos de la libertad, Centro de Estudios Públicos sobre la Libertad, Buenos Aires, 1975.

- (1976): Derecho, legislación y libertad. Una nueva formulación de los principios liberales de la justicia y de la economía política, vol. II, El espejismo de la justicia social, Universidad Francisco Marroquín, Guatemala, 1979.

- (1979): Derecho, legislación y libertad. Una nueva formulación de los principios liberales de la justicia y de la economía política, vol. III, El orden político en una sociedad libre, Universidad Francisco Marroquín, Guatemala, 1982.

Huerta DE SOTO, J. (1987): Lecturas de economía política, vol. 1, Unión Editorial, Madrid, 1990.

- (1992): Socialismo, cálculo económico y función empresarial, Unión Editorial, Madrid, 3. a ed., 2005.

JHERING, R. VON (1852-1865): El espiritu del derecho romano en sus diferentes etapas de desarrollo, T. IV, De Bailly-Baillere e Hijos, Madrid, 1892.

- (1877-1883): El fin en el derecho, Bibliografía Omeba, Buenos Aires, 1960.

KIRZNER, I. (1973): Competencia y función empresarial, Unión Editorial, Madrid, 1998.

- (1992): The Meaning of Market Process. Essays in the Development of Modern Austrian Economics, Routledge, London/New York. 
LACHMANN, L. (1966): «El significado de la escuela austriaca de economía en la historia de las ideas», en Libertas, n. ․ㅡㄹ 27, Octubre, 1997 (http:/ / www.eseade.edu.ar/files/Libertas/18_11_ Lachmann.pdf).

Leoni, B. (1961): La libertad y la ley, Centro de Estudios sobre la Libertad, Buenos Aires, 1961.

LuKÁcs, G. (1923): Historia y conciencia de clase, 2 vols., Sarpe, Madrid, 1985.

Menger, C. (1883): Problems in Economics and Sociology, University of Illinois Press, Urbana, Illinois, 1963.

Mises, L. von (1949): La acción humana, Unión Editorial, Madrid, 5. ㄹ ed., 1995.

Montaigne, M. DE (1580): Ensayos de Montaigne seguidos de todas sus cartas conocidas hasta el día, 2 vols. Casa Editorial Garnier Hermanos, París 1912.

PAšUKAnis, E. (1924): Teoría general del derecho y marxismo, Labor Universitaria, Barcelona, 1976.

Popper, K. (1945): La sociedad abierta y sus enemigos, Paidós, Barcelona, 1994.

Risolia, M.A. (1958): Soberanía y crisis del contrato en nuestra legislación civil, Abeledo-Perrot, Buenos Aires.

SARTORI, G. (1965): Aspectos de la democracia, Limusa-Wiley, México.

SмIтH, A. (1978): Lectures on Jurisprudence, Liberty Fund, Indianapolis, 1982.

SPENCER, H. (1884): El individuo contra el Estado, Orbis, Madrid, 1984. 